\title{
The Effects of Tannic Acid on Some Properties of Cow Gelatin’s Film
}

Dana $\mathrm{E}^{1}$, Ardestani $\mathrm{SS}^{2}$ and Khodabandehlo $\mathrm{H}^{1 *}$

${ }^{1}$ Department of Chemical Engineering, Shahrood Branch, Islamic Azad University, Shahrood, Iran

${ }^{2}$ Department of Chemical Engineering, Food industry, Islamic Azad university of Science and Research unit, Tehran, Iran

\begin{abstract}
This paper mainly aimed on the effect of tannic acid's effect on chemo-physical and mechanical characteristic properties of cow's gelatin film. Through this research the cow gelatin film along with tannic acid with different viscosity for; 0 , 250 , 500 , 1000 ppm via costing solvent methods examined and experimented mechanically and physico-chemical with National American Standard methods. The increasing mechanical pulling resistance test shows the reduction percentages of pulling properties due to the increasing viscosity of the tannic acid. The physicochemical properties of solvent such as: water absorbing, water solution capability, water steam influence tendency, oxygen attraction will surprisingly decrease when tannic acid concentration increases $(\mathrm{P}<0.05)$. In general, according to our research; in food industries, "the eatable films are used as an active packing".
\end{abstract}

Keywords: Tannic acid; Cow gelatin; Costing method; Mechanical properties

\section{Introduction}

Gelatin films, with its many potential benefits, are widely used in the pharmaceutical/medical and cosmetic products, as well as in food industries to improve the shelf life of the content by controlling water absorption, oxygen permeation and aroma loss [1-4]. Despite this unique property, gelatin film does not have ideal mechanical properties and water vapor barrier, which could limit its applications [5-7]. Interactions between gelatin and phenolic molecules, such as ferulic acid and tannin acid, have been reported to modify optical transparency [8]. Enhanced mechanical properties could also be obtained by treating gelatin with glyoxal and genipin, but high cost of material and potential toxicity limits its possible application [9-11]. In recent years, biodegradable edible films from natural biological materials are gaining importance. Among the natural materials, protein based edible films are the most appealing for their nutritional value and enhancement of the quality and safety of food products [12]. Environmental concerns and a more reasonable use of fossil resources have amounted to a growing interest for renewable and biodegradable packaging materials [13]. However, one of the main challenges of using cellulose-based packaging materials (such as cups, plates, trays and food containers) is the poor formability of cellulose [14].

\section{Materials and Methods}

\section{Materials}

Cow gelatin purchased from Canadian Sigma co. Liang Traco (the eatable glycerol) from Penang-Malaysia magnesium nitrate and $\mathrm{P}_{2} \mathrm{O}_{5}$ to control the humidity off of Sigma Aldrich (Kuala Lumpur-Malaysia). Other necessary materials provided from local lab. Cow gelatin and Fluka tannic acid purchased from Sigma Co of Germany. Eatable glycerol sorbitol, magnesium nitrate and calcium chloride the isotherm salts including sulfuric acid, lithium chloride, magnesium chloride, potassium carbonate, magnesium nitrate, potassium iodide, sodium chloride, potassium bromide, and potassium chloride purchased from Germen Marquee co.

\section{Methods}

Preparations and examinations: Picking up different weights of $0.1,0.05,0.025$ grams of Tonic acid and reach to volume in balloon of 100. 20 gram of $\mathrm{NaOH}$ along with $50 \mathrm{cc}$ distilled water reach to the volume. We placed the $0.1,0.05,0.025$ grams of Tannic acid has reached to the volume, adjacent to a magnet inside the shrilled containers together we put them inside bigger dish contained a thermometer on a hot plate. By adding few drops of $\mathrm{NaOH}$ we reach the solution to $\mathrm{pH} 10$. Once the temperature to 60 Celsius, we enter the Oxygen to the solution. Then we add 9.2 grams of Cow gelatin to the compound, after 30 minutes we add the plasticizer. Then adjust the frame and the plate properly. Now we pour 50 grams of solution of ben-miry in center part of plate to spread out in plate. After 24 hours we separate when the dried film and place in desiccator so the film gets damped evenly. The thickness of film measured with hand held microsites with the sensitivity of 0.01 millimeter. And randomly average gained from 5 points of plate according to WVP calculations in Japan -MitutoyoTokyo. An examination consists of: mechanical specialty, physical properties (the capability of solution $\mathrm{n}$ absorbing water with different Tannic acid viscosity) evaluations.

Statistics analysis: Computerized Enova, Tokay or donken tests are used for physical or mechanical specialties tests of different kinds of films at $5 \%$. Statistics analysis has done by SPSS17.

\section{Results Analysis}

\section{Visual analyzing}

In Recent inspection, the gelatin films turning from yellow to brown as the tannic acid concentration increases.

\section{The effects of acid tannic on the cow's gelatin film thicknesses analysis}

Experiments results show there no significant effect on different film thicknesses. However the general thickness is between $13-15 \mathrm{~mm}$ (Table 1).

*Corresonding author: Khodabandehlo $\mathrm{H}$, Department of Chemica Engineering, Shahrood Branch, Islamic Azad University, Shahrood, Iran, E-mail: hessamkhodabandehlo@yahoo.com

Received June 05, 2015; Accepted July 14, 2015; Published July 21, 2015

Citation: Dana E, Ardestani SS, Khodabandehlo H (2015) The Effects of Tannic Acid on Some Properties of Cow Gelatin's Film. J Food Process Technol 6: 491. doi:10.4172/2157-7110.1000491

Copyright: (c) 2015 Dana E, et al. This is an open-access article distributed under the terms of the Creative Commons Attribution License, which permits unrestricted use, distribution, and reproduction in any medium, provided the original author and source are credited. 


\begin{tabular}{|c|c|}
\hline Sample & thickness \\
\hline reference & $(13 \pm 0.1)^{\mathrm{a}}$ \\
\hline 250PPM acid Tannic & $(14 \pm 0.1)^{\mathrm{a}}$ \\
\hline 500 PPM acid Tannic & $(13 \pm 0.1)^{\mathrm{a}}$ \\
\hline 1000 PPM acid Tannic & $(15 \pm 0.1)^{\mathrm{a}}$ \\
\hline
\end{tabular}

Letter in table (a) presenting the tolerances of $0.05 \%$.

Table 1: Reviews cow gelatin film thickness as compared with the control sample.

\begin{tabular}{|c|c|c|c|}
\hline $\begin{array}{c}\text { Tannic acid } \\
\text { (ppm) }\end{array}$ & $\begin{array}{c}\text { Tensile } \\
\text { Strength (MP) }\end{array}$ & $\begin{array}{c}\text { Elongation at } \\
\text { break (\%) }\end{array}$ & $\begin{array}{c}\text { Young's } \\
\text { modulus (GPa) }\end{array}$ \\
\hline 0 & $33.63 \pm 0.74^{\mathrm{d}}$ & $27.1 \pm 4.2^{\mathrm{a}}$ & $0.395 \pm 0.042^{\mathrm{c}}$ \\
\hline 250 & $34.96 \pm 0.33^{\mathrm{c}}$ & $22.1 \pm 2.5^{\mathrm{b}}$ & $0.402 \pm 0.061^{\mathrm{b}}$ \\
\hline 500 & $35.33 \pm 0.43^{\mathrm{b}}$ & $18.4 \pm 4.1^{\mathrm{c}}$ & $0.413 \pm 0.024^{\mathrm{b}}$ \\
\hline 1000 & $37.22 \pm 0.95^{\mathrm{a}}$ & $11.3 \pm 3.8$ & $0.491 \pm 0.054^{\mathrm{a}}$ \\
\hline
\end{tabular}

Letters in table $(a, b, c, d)$ presenting the tolerances of $0.05 \%$.

Table 2: Effect of different concentration of tannic acid of mechanical properties of film.

\begin{tabular}{|c|c|c|}
\hline Tannic acid $(\mathbf{p p m})$ & WVP $\times \mathbf{1 0 1 1}\left[\mathbf{g ~ m}^{-1} \mathbf{~ s}^{-1} \mathbf{P a}^{-1}\right]$ & O. $\mathbf{P}\left[\mathbf{c m}^{\mathbf{3}} \mathbf{m} /\left(\mathbf{m}^{-\mathbf{2}} \mathbf{d a y}\right)\right]$ \\
\hline 0 & $8.9 \pm 0.31^{\mathrm{a}}$ & $226.18 \pm 7.92^{\mathrm{a}}$ \\
\hline 250 & $7.10 \pm 0.33^{\mathrm{b}}$ & $200.11 \pm 874^{\mathrm{b}}$ \\
\hline 500 & $3.98 \pm 0.450^{\mathrm{c}}$ & $143.57 \pm 2.25^{\mathrm{c}}$ \\
\hline 1000 & $161 \pm 0.13^{\mathrm{d}}$ & $97.23 \pm 4.40^{\mathrm{d}}$ \\
\hline
\end{tabular}

Letters in table $(a, b, c, d)$ presenting the tolerances of $0.05 \%$.

Table 3: Effect of tannic acid to permeability oxygen and water vapor on gelatin films.

Analysis and comparison mechanical properties of control film with different concentration of tannic acid

As it is shown in Table 2, the mechanical properties of cow film will increases when the concentration of Tannic Acid increases between zeros to 1000 PPM the stretch resistance of film also increases (between 33 mega Pascal to about 37 mega Pascal $(\mathrm{p}<0.05)$. In this research it also shows the film stretches reduce from 27 to 11 percent depending on tannic acid concentration increasing value $(\mathrm{p}<0.5)$. Data presenting the average standard \pm tolerances Letters in table $(\mathrm{a}, \mathrm{b}, \mathrm{c}, \mathrm{d})$ presenting the tolerances of $0.05 \%$.

\section{The water steam absorbent potential (WVP)}

The Water steam absorbent potential (it better to write water resistance ability) has negative effect on film life. Table 3 shows these effects. Gelatin Films with different concentration of tannic acid against water effects will improve with increasing the concentration of tannic acid. The later chemical bods created by tannic acid in compare of matrix bio composite are the cause of resistance. Therefore these bonds create the way out for water molecules.

\section{Oxygen influence resistance on film}

Influence ability in respect to gas and other volatile materials in poly saccharide are under variety of effects as- region characterizations in compare amorphous region, the level of polymeric chain sensitivity and inside chaining concentration tendency of polymers. In this research as it shows in Table 4 in corrected gelatin films, as the tannic acid concentration increases, the film tendency towards absorbing oxygen decreases. Data presenting the average standard \pm tolerances letters in table (a, b, c, d) presenting the tolerances of $0.05 \%$.

\section{Effect of tannic acid on physiochemical property of the gelatin} films

Moisture content, solubility in water and water adsorption capacity: Table 4 indicates the moisture content, solubility in water and water absorption capacity for gelatin films and samples treated with tannic acid. Data with \pm shows the average tolerance. English letters $(\mathrm{a}, \mathrm{b}, \mathrm{c}, \mathrm{d})$ is the $5 \%$ meaningful probable average variation.

As it is specified in the table with adding tannic acid to the gelatin film, film water absorbing capacity (WAC) greatly reduces as acid increases $(p<0.05)$. The reason is because hydroxyl group exist in gelatin film are water solvable and the presence of tannic acid will block such relation between water and the gel-film. Instead the tannic acid repels the water on bio-polymer matrix and stops to absorb it by gel. The Bio-polymer composites water Solvability can be also reduced by lipid, protein based, and Nano particles compound adding to gelatin film (Figures 1 and 2).

Evaluation of the transmission and absorption of light in the visible and ultraviolet zone from the gelatin films: In following Figures 3 and 4, the absorption and trans-passing the light value with 200 to 1100 Nanometer wave length of bio-composite film contain tannic acid with different concentration is showing. As it is shown in conclusion by adding tannic acid to the film visible light has passed through and ultra violet signal gradually blocked as the acid concentration has increased as at $1000 \mathrm{ppm}$ ultra-wave length has completely blocked through.

Finding bond with FTIR method: FTIR spectrum of matrix Gelatin films in following Figure 5 and corrected matrix gelatin film with tannic acid in Figure 6, clearly shows active groups with using acid is changed and some recently appeared. This shows the transaction is entirely chemical with lateral chemical bonds and has been the element of actual cause of gelatin film's improvement.

\begin{tabular}{|c|c|c|c|}
\hline $\begin{array}{c}\text { Tannic } \\
\text { Acid (ppm) }\end{array}$ & $\begin{array}{c}\text { Damp } \\
\mathbf{( 5 8 \% )}\end{array}$ & \%Solubility & $\begin{array}{c}\text { Water Absorbent } \\
(\mathbf{a})\end{array}$ \\
\hline 0 & $14.88 \pm 0.34^{\mathrm{a}}$ & $30.10 \pm 1.23^{2}$ & $9.93 \pm 0.33^{\mathrm{a}}$ \\
\hline 250 & $14.88 \pm 0.34^{\mathrm{a}}$ & $28.16 \pm 1.41^{\mathrm{a}}$ & $8.78 \pm .18^{\mathrm{b}}$ \\
\hline 500 & $13.88 \pm 0.08^{\mathrm{b}}$ & $26.85 \pm 1.29^{\mathrm{b}}$ & $8.74 \pm 0.11^{\mathrm{b}}$ \\
\hline 1000 & $13.61 \pm 0.23^{\mathrm{b}}$ & $22.40 \pm 2.01^{\mathrm{c}}$ & $7.32 \pm .25^{\mathrm{c}}$ \\
\hline
\end{tabular}

Letters in table (a,b,c,d) presenting the tolerances of $0.05 \%$. (a) - (gr wet material/ gr dry material).

Table 4: Moisture content, Solubility in water and water adsorption capacity.

A

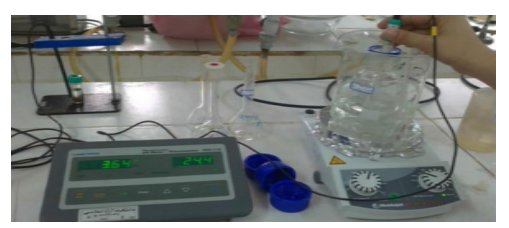

$\mathrm{B}$

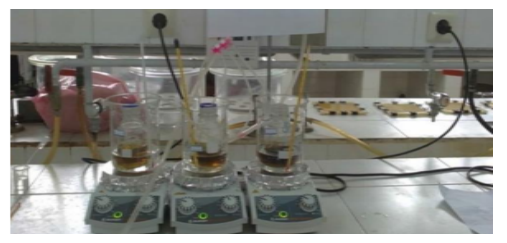

Figure 1: A and B cow gelatin film preparation with Tannic acid. 
Citation: Dana E, Ardestani SS, Khodabandehlo H (2015) The Effects of Tannic Acid on Some Properties of Cow Gelatin's Film. J Food Process Technol 6: 491. doi:10.4172/2157-7110.1000491

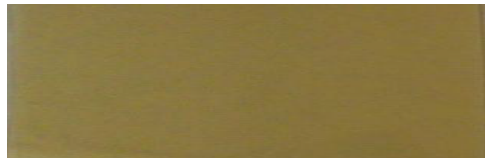

A: $(250 \mathrm{ppm})$

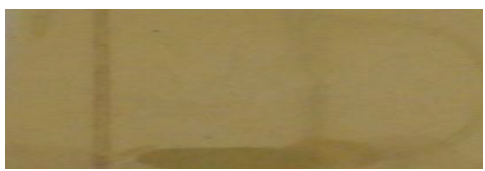

B: $(500 \mathrm{ppm})$

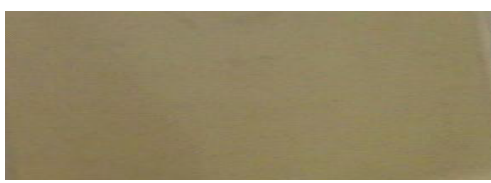

C: $(1000 \mathrm{ppm})$

Figure 2: Color inspection on film's with 250-500-1000 ppm acid tannic.

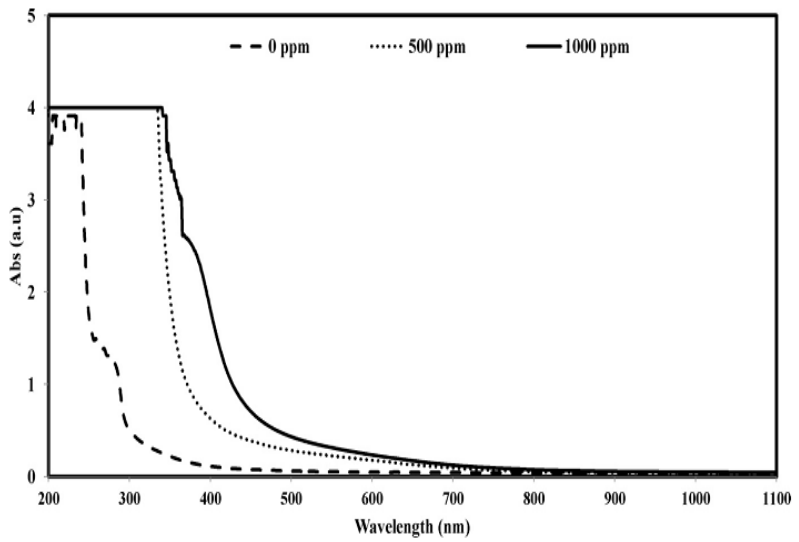

Figure 3: Amount of light absorption by bio-composite film that treatment with tannic acid in wavelengths of $200-1100 \mathrm{~nm}$.

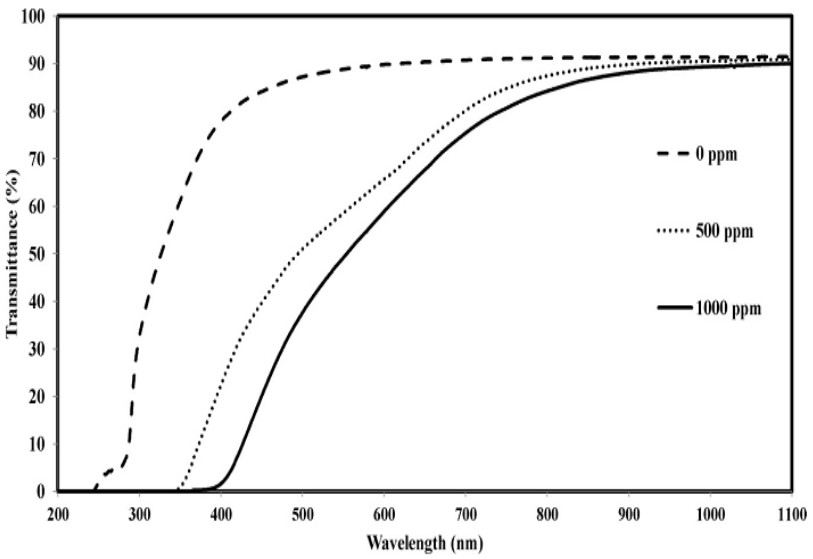

Figure 4: The Bio-composite gelatin films contained tannic acid light absorption capacity through wave lengths of 200-1100 nm.

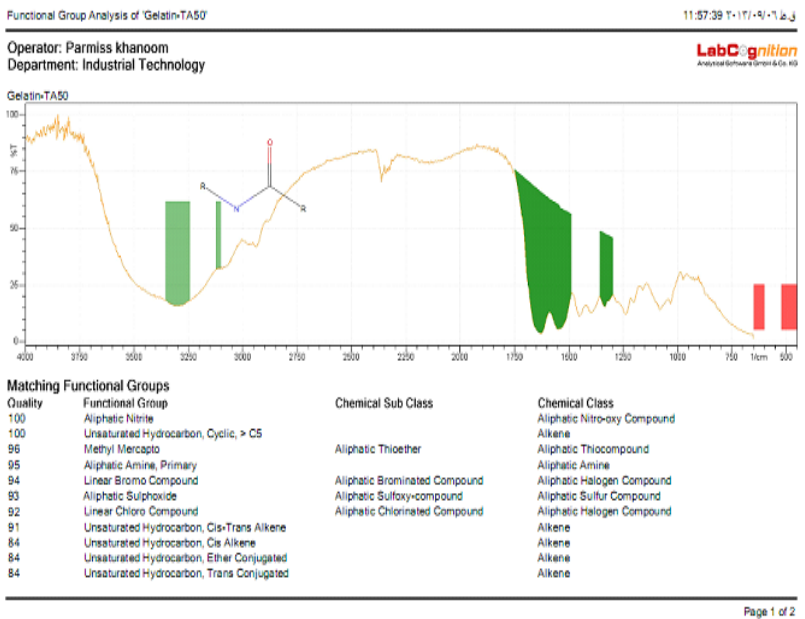

Figure 5: FTIR spectrum for gelatin film

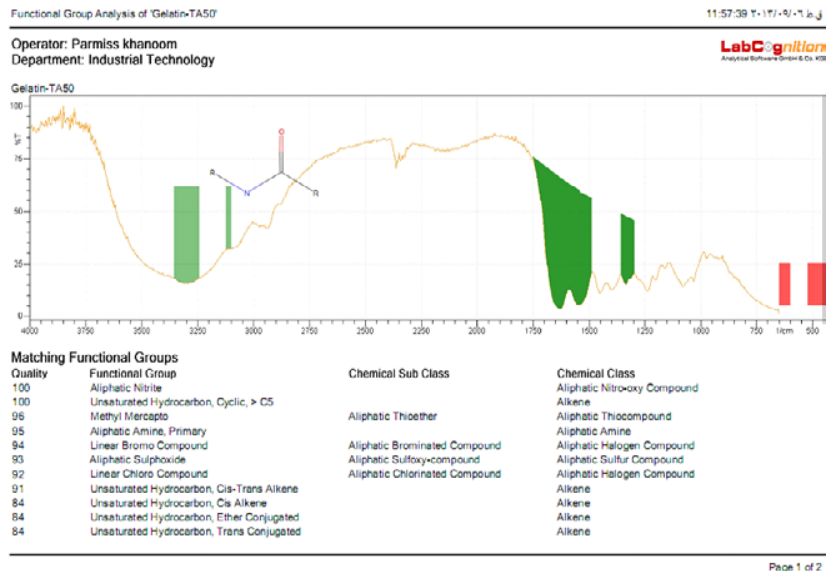

Figure 6: FTIR gelatin film contain 500 PPM tannic acids.

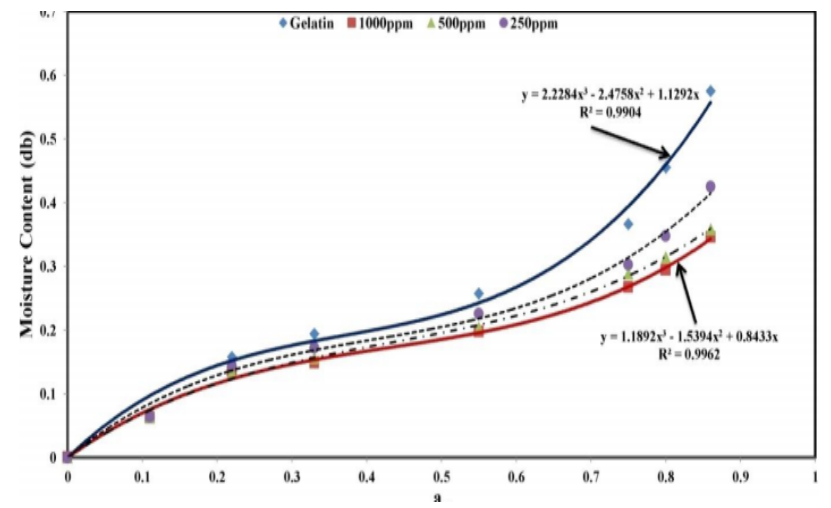

Figure 7: A model of polynomial equilibrium absorption (degree=3) for gelatin films in comparison with gelatin bio-composite contain acid tannic.

\section{Study of polynomials models absorbing equilibrium}

Figure 7 shows a modeled curve of polynomial for Gelatin film and films contain tannic acid equilibrium absorption. As it is illustrated in this model with lateral bonds and with tannic acid's help could affect to absorbing equality and pulling it down instead. 
Citation: Dana E, Ardestani SS, Khodabandehlo H (2015) The Effects of Tannic Acid on Some Properties of Cow Gelatin's Film. J Food Process Technol 6: 491. doi:10.4172/2157-7110.1000491

\section{Conclusion}

The results show with increase of acid tannic concentration, Tensile strength have significant grow up from 33 to $37 \mathrm{Mpa}(\mathrm{p}<0.05)$. Also, found that the elongation percentage significant decrease from $27 \%$ to $11 \%(\mathrm{p}<0.05)$ as well as the results showed with increase the particle, Some parameters similar, water solubility, permeability to oxygen and the rate of water absorption significant decreased $(\mathrm{p}<0.05)$. However with increase of tannic acid concentration the amount of permeability to water vapor and light passed decreased $(\mathrm{p}<0.05)$.

\section{References}

1. Achet $D$, He XW (1995) Determination of the renaturation level in gelatin films Polymer 36: 787- 791.

2. Bigi A, Panzavolta S, Rubini K (2004) Relationship between triple-helix conten and mechanical properties of gelatin film. Biomaterials 25: 5675-5680.

3. Cao N, Fu Y, He J (2007) Preparation and physical properties of soy protein isolate and gelatin composite film. Food Hydrocolloids 21: 1153-1162.

4. Irwandi J, Faridayanti S, Mohamed ESM, Hamzah MS, Torla HH, et al. (2009) Extraction and characterization of gelatin from different marine fish species in Malaysia. International Food Research Journal 16: 381-389.

5. Cao N, Fu Y, He J (2007) Mechanical properties of gelatin films cross-linked, respectively, by ferulic acid and tannin acid. Food Hydrocolloids 21: 575-584.
6. Bourtoom T (2008) Edible films and coatings: Characteristics and properties. International Food Research Journal 15: 237-248.

7. Bourtoom T (2009) Edible protein films: Properties enhancement. International Food Research Journal 16: 1-9.

8. Peña C, De la Caba K, Eceiza A, Ruseckaite R, Mondragon I (2010) Enhancing water repellence and mechanical properties of gelatin films by tannin addition. Bioresource Technology 101: 6836-6842.

9. Bigi A, Cojazzi G, Panzavolta S, Rubini K, Roveri N (2001) Mechanical and thermal properties of gelatin films at different degrees of glutaraldehyde cross linking. Biomaterials 22: 763-768.

10. Bigi A, Cojazzi G, Panzavolta S, Roveri N, Rubini K(2002) Stabilization of gelatin films by cross linking with genipin. Biomaterials 23: 4827-4832.

11. Spanneberg R, Osswald F, Kolesov I, Anton W, Radusch HJ, et al. (2010) Model studies on chemical and textural modifications in gelatin films by reaction with glyoxal and glycolaldehyde. Journal of Agricultural and Food Chemistry 58: $3580-3585$

12. Gennadios A, Weller CL, Hanna MA (1997) Soy protein/fatty acid films and coatings. Inform 8: 622-623.

13. Rhim J (2010) Food Sci Biotechnol 19: 243-247.

14. Vishtal E, Retulainen E (2012) Deep-drawing of paper and paperboard: The role of material properties bioresources $7:$ 4424-4450. 